\section{IJ§ER}

ISSN: 2149-5939
International Journal of Social Sciences and Education Research

Online, http://dergipark.gov.tr/ijsser

Volume: 3(3), 2017

\title{
Dijital kamusal alanda grup iletişimi: WeChat örneği
}

\author{
Group communication at digital public space: WeChat sample
}

Tülay Yazıc1 ${ }^{1} \quad$ Xiarepati Tuerxun ${ }^{2}$

Received Date: 10 / $02 / 2017$

Accepted Date: 08 / $06 / 2017$

$\ddot{O} z$

Teknolojinin insan yaşamına sunduğu farklılıklar ve yeni iletişim yöntemleri sosyal hayat kavramını yaşama biçimini de değiştirmiştir. Sosyal medya araçları içerisinde son dönemlerde çok yaygın olarak kullanılan WeChat uygulaması, kişisel özelliklere göre farklılaşan toplumların ortaya çıkmasının yanı sıra iletişim ve etkileşim içerisinde bulunmalarını sağlayarak kamusal alanı dijital ortama taşımaktadır. Çalışmanın amacı, Çin'de çok yaygın şekilde kullanılan sosyal ăg sitesi WeChat iletişim platformunu, kamusal alan bağlamında grup iletişiminin önemi ve kullanım amaçları açısından incelemek ve sosyalleşmedeki etkisini ortaya çıkarmaktır. Çalışmada, grup iletişimi ve dijital kamusal alan üzerine literatür araştırmast ile birlikte aktif olarak WeChat grubunda yer alan üyeler ile derinlemesine mülakat gerçekleştirilmiş ve elde edilen veriler değerlendirilmiştir.

Anahtar Kelimeler: Sosyal Medya, Grup Iletişimi, Digital Kamusal Alan, WeChat

\begin{abstract}
Technological differences in human life and new communication methods have changed the way of living the concept of social life. The WeChat application, which has been widely used in social media recently, is a free, is carrying digital public space by providing communication and interaction as well as the emergence of differentiated societies according to personal characteristics.

Purpose of the study examines the communication platform in terms of the importance and use of group communication in the context of public space and to reveal its social effect, the social networking site WeChat, which is used extensively in China. In the study, with literature research on group communication and digital public space, in-depth interviews conducted with the members of the WeChat group actively and the obtained data were evaluated.
\end{abstract}

Keywords: Social Media, Group Communication, Digital Public Space, WeChat

\section{Giriş}

Gündelik hayattaki iletişim ortamlarının teknoloji ile birlikte değişmesi sonucunda ortaya çıkan sosyal ağ kavramı iletişim biçimlerini de değiştirmiştir. Birbirlerinde farklı olmasına rağmen ortak ilgi alanları veya meslek gruplarında yer alan insanların sanal topluluklar oluşturarak iletişim kurdukları sosyal ağlar, duyuru veya bilgi alışverişine dayalı iletişim yöntemleri temelinde gerçekleşmektedir. Zamansız ve mekansız iletişim olanağının olduğu sosyal ağlar hem mevcut iletişimi devam ettirmekte hem de yeni ortamların ve kanalların oluşmasına olanak sağlamaktadır.

\footnotetext{
${ }^{1}$ Arş. Gör., Kocaeli Üniversitesi İletişim Fakültesi Halkla İlişkiler ve Tanıtım Böl., Kocaeli/TÜRKIYE, tulyaz@,hotmail.com

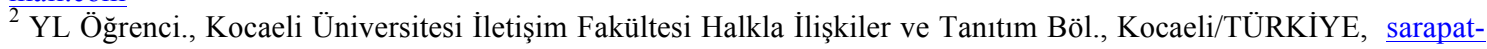
tursun komul@hotmail.com
} 
Yazıc1, T., Tuerxun, X. (2017). Group communication at digital public space: WeChat sample. International

Journal of Social Sciences and Education Research, 3(3), 966-980.

Küreselleşmeyle birlikte gelişen ve değişen ve bu süreçte yeni olma özelliğini devam ettiren iletişim ortamları kurallar, yasaklar ve engellerden bağımsız, herkese açık ve kolay erişebilir ortamlar yaratması açısından katılım odaklı yeni alanlar yaratmaktadır. Bu bağlamda kamusal alan kavramına da yeni ve farklı bir boyut kazandırmaktadır.

Teknolojinin güç haline geldiği yeni toplumlarda bilgi odaklı toplumsal değişimler yaşanmaktadır. Bilgiye sahip ve bilgiyi yöneten toplumlar iletişim kanallarını ve kullanımını da belirlemektedir. 2000"li yıllardan sonra sosyal medya, internet ve ak1ll telefon teknolojilerinin gelişmesiyle birey ve grupların internet üzerinden birbirleriyle gerçek zamanlı diyalog kurması, çift yönlü veri ve enformasyon paylaşımı yaygınlaşmıştır. Yeni medya ortamları farklı toplumsal muhalefet odaklarının, kurumların ve grupların bir araya gelerek örgütlenebildikleri ve fikirlerini rahatça duyurabildikleri bir mecra durumuna gelmiştir (Sayimer, 2014, s. 97-98).

Teknoloji ile birlikte sosyal hayatın her alanında yaşanan değişiklik devrimi neticesinde toplumsal kamusal alan değişmiş ve dijital ortamlar yeni kamusal alanlar olmaya başlamıştır. Sanal ortamlarda gerçekleşen bilgi ve içerik paylaşımları ve bunlarla ilgili oluşan tartışma ortamları sanal ortamda gün geçtikçe daha etkili ve geniş bir alanda var olmaktadır. Geleneksel medyanın temsil ettiği kamusal alan iletişim ve bilgi teknolojilerinde yaşanan hızlı ilerlemeler sonucunda yeni bir boyut kazanmıştır.

\section{Kamusal alan}

Kamusal alan, farklı bireylerin, farklı toplumsal kesimlerin, farklı fikirlerin medeni ve demokratik biçimde bir arada bulunmalarına ve yarışmalarına imkân veren bir alandır. Özgürlüklerin ve hakların hayata geçirildiği ve yaşandığı bir alan olması nedeniyle özgürlüklerin yok edildiği bir alan değildir. İnsanların birlikte etkileşim halinde yaşadığı, her türlü farklılığın var olduğu bir alandır. Devlet kamusal alanın içindeki aktörlerden biri olmasına rağmen kamusal alan, devlete ait alan/olan değildir (Ercins, 2013, s. 311).

Habermas kamusal alanı, özel şahısların kendilerini ilgilendiren ortak bir sorun etrafında akıl yürüterek, ussal bir tartışma içine girerek elde ettikleri, ortak bir kanı ve kamuoyu oluşturdukları süreç, araç ve mekanların tanımlandığı yaşam alanı (Yavaşgel, 2014, s. 69) olarak tanımlamaktadır. Ayrıca Habermas, toplantıları, kapalı toplumlarınkinden farklı olarak herkese açık olduğunda "kamusal" olarak adlandırmaktadır. Devletin sahip olduğu "kamu erki" kendi hukukuna tabi olanların ortak kamusal selametini sağlama görevine sahip olması nedeniyle ortaya çıkmaktadır. Kamu kendisini özel alandan ayrı bir alan olarak ortaya koymakta ve bazen devlet organları bazen de halka iletişim hizmeti veren basın gibi medya unsurları "kamusal organlar" olarak görülmektedir (Habermas, 2003, s. 58-59).

Habermas'ın kamusal alan tanımından çıkan özellikler şu şekilde sıralanabilir:

1. Katılım herkese açıktır. "herkesçe erişebilirlik" ilk temel şarttır.

2. Katılımda yer alan herkes eşit ve özgürdür.

3. Konuşmalar "alenidir".

4. Yurttaşların katılımının önündeki engellerin kaldırılmış olması ve bu alana erişimin garanti altına alınmış olması gerekir.

5. Kamu alanı, devlet kurumlarının dışında yer alır.

6. Genel yarara ilişkin olması dışında bir gündem kısıtlaması yoktur. Ayrıca bir konunun genel yarara ilişkin olup olmadığı da bu tartışmalarda tayin edilebilir (Yükselbaba, 2008, s. 251). 
Yazıcı, T., Tuerxun, X. (2017). Dijital kamusal alanda grup iletişimi: WeChat örneği. International Journal of Social Sciences and Education Research, 3(3), 966-980.

\subsection{Kamusal alan ve özel alan ilişkisi}

Kamusal ve özel alan ayrımı arasında bir karşıtlık ilişkisi vardır ve bu iki kavramı ayırt etmek için iki kriter belirlenebilir.

Birinci kriter "görünürlük" tür. Gizli olanla açık olan, ortaya çıkarılan ya da erişilebilir olan ifade edilmektedir. İkinci kriter "kolektiflik”tir. Bireysel olan ya da bireye ilişkin olanla, toplumsal olan ile toplumsal yarara yönelik olan arasındaki ayrımı belirtir.

Bu kriterler; kamusal alanla özel alan ayrımını netleştirmenin yanı sıra, kamusal ile özel alanın zaman zaman iç içe geçme durumunu ya da iki birbirinden farklı boyutlara ve anlamlara göre değerlendirileceğini belirtmektedir. Bu durum kamusal ve özel alan ayrımında çok çeşitli kriterler bulunduğunun göstergesidir (Yükselbaba, 2008, s. 76).

Kamusal alan tartışmasında, ortaya çıkan en önemli unsurlardan biri de "özel alan" kavramıdır. Bu ayrım daha çok, "kamusal alan" ne değildir sorusuna istinaden verilen bir cevap olarak, Habermas'ın da belirttiği gibi, kamusal olan ve özel olan ile ilişkisi içinde belirlenir (Sarıbay, 2000, s. 3).

\subsection{Sosyal medya, ağ toplumu, kamusal alan dönüşümü}

Web 2.0 kullanıcıların diğer kullanıcılarla içerik yayınlama ve değişim olanağı sağlayan siteler ve programlar olarak tanımlanırken; sosyal medya bu teknoloji üzerine kurulan sosyal etkileşimi, topluluk oluşumunu ve işbirliği projelerini gerçekleştirmeyi sağlayan siteler olarak tanımlanmaktadır (Hazar, 2011, s.154). Sosyal medya web 2.0 sayesinde geliştirilmiş, kullanıcılara içerik yayınlama ve değişim olanağı sağlayan yeni bir internet inovasyonu süreci olarak tanımlamak için oluşturulmuş bir dönem olarak tanımlanmıştır. Sosyal medya; forumlar, içerik blogları, mikrobloglar (Twitter), sosyal ağ siteleri (Facebook), iş ağları (LinkedIn), video paylaşım siteleri (Youtube), işbirliği sonucu oluşan web siteleri (Wikipedia) ve sanal dünyalar (Second Life) gibi çok geniş bir alanı kapsamaktadır (Kwon\&Sung, 2011, s. 5).

Sosyal medya; katılımcılarının dijital ortamlarda kendilerini ifade etme, sosyal çevre edinme, gruplara katılma ve bu ortamlara fikir ve görüşleriyle yorum ve paylaşım yaparak katkıda bulunma imkânı sağlayan sosyal içerikli web siteleri olarak tanımlanabilir (Köksal \& Özdemir, 2013, s. 325).

Sosyal medyanın dünyası içerisinde, içinde bulunduğumuz toplumu ifade eden diğer bir tanımlama da ağ toplumudur. Çağımız toplumu artık, herkesin her yerde ve her zaman istediği yere bağlanabildiği çağdır ve 'ağ toplumu' olarak tanımlanmaktadır. A ̆g toplumununa etkinlik kazandıran en önemli özellik iki yönlü iletişim ve etkileşimdir (Kesim, 2008, s. 5-6).

Jan Van Dijk'e (2016, s. 40-41) göre ağ toplumu, sosyal ve medya ağlarından oluşan bir yapının toplumun her seviyesindeki örgütlenme biçimini belirlediği modern bir toplum türü olarak tanımlanmaktadır. Bu tanım toplumdaki tüm faaliyetlerin yüksek enformasyon yoğunluğuna sahip belirli bir öz ile belirtilen enformasyon toplumuyla karşılaştırılabilir. Ayrıca gruplar, örgütler ve topluluklar altyapısına sahip modern toplumların daha önce ortaya çıkmış bir türü olan kitle toplumu ile de kıyaslanabilir. Gruplar, topluluklar, örgütler gibi her türlü küme içerisinde düzenlenmiş yerel bireysel birimlerin büyük bir çoğunluğunu birbirine bağlayan uzak mesafeli bağlantılardan oluşmaktadırlar. Böylece giderek azalan sayıda ayrılık dereceleri ve daha yüksek bağlanabilirlik sayesinde giderek artan sayıda "küçük dünya" oluşturmaktadır. 
Yazıc1, T., Tuerxun, X. (2017). Group communication at digital public space: WeChat sample. International

Journal of Social Sciences and Education Research, 3(3), 966-980.

Jürgen Habermas'ın ortaya attığ kamusal alan kavramı; insanların fikirlerini paylaşabildiği bir ortam olarak ifade edilirken, devlet ile ekonomiden ayrı olarak kararları değiştirme veya etkileme olanağına sahip olunduğunu da vurgulamaktadır. Geçmiş yıllarda bireyler yüz yüze iletişim kurmayı tercih ederek, fiziksel olarak bir arada olduğu sohbetlerde fikir alış verişi gerçekleştirmekteydi. Bu karşılıklı etkileşimden sonra da ortaya çıkan fikirlerin geniş kitleler tarafından kabul görmesi ise kamusal alanın oluşmasını sağlamaktaydı. Günümüzde fiziksel topluluk alanları olarak kabul edilen kahvehanelerde gerçekleşen sohbetler artık zamandan ve mekandan bağımsız hızlı ve etkileşimli çevrimiçi platformlarda gerçekleşmektedir.

Bilgi ve iletişim teknolojilerindeki gelişmelerle birlikte bireyler güncel, sanatsal, ekonomik, eğitimsel ya da siyasal konularda sanal ortamlarda bir araya gelerek mekânsız ve kimliksiz olarak fikirlerini öne sürmekte, gruplar oluşturabilmektedir. Bloglar, sosyal ağlar gibi sanal oluşumlar bireylerin bir araya geldiği, tartışma ortamı oluşturdukları yerlerdir. Habermas kamusal alan tanımlamasının özellikle kitle iletişiminin gelişimiyle dönüşüm yaşadığını belirtse de günümüzdeki sanal kamusal alan, salon kamusal alanıyla benzerlik göstermektedir (Varol, 2010, s. 126-127).

\section{Sanal ortamda grup iletişimi ve WeChat}

Toplum içinde bulunduğumuz ilişkiler bütünüdür. Bu ilişkiler, çoğunlukla bir toplumsal yapı içinde toplumsal gruplar aracılığıyla gerçekleşir. Her birey değişik koşullarda farklı gruplar içinde bulunur. Toplumsal gruplar, bireylerin bir amaç doğrultusunda karşılıklı etkileşimde bulunması ile gerçekleşir. Gruptaki her bireyin, öteki insanlara göre belli bir yeri ve bu yerin gerektirdiği bir rolü vardır (Megep, 2012, s. 5). İnsan ilişkileri toplumsal grupların içinde kurulur. Teknolojinin gelişmesi ile birlikte fiziksel olarak gerçekleşen iletişim ortamları sanal ortamlarda gerçekleşmektedir. Sanal ortamlarda bireyler sosyal ağlarla tercih ettiği bir veya birden fazla grubun üyesi olabilir ve bu grupta yer alan insanlarla etkileşim haline geçebilir. Bu noktada bağlayıcı olan özellik kişinin ilgi alanları ve tercihleri doğrultusunda katılımcı olması ile ilgilidir.

Bu bağlamda sosyal ortamlarda grup iletişiminde önemli bir yere sahip olan Wecaht uygulamas1 etkin bir kullanım alanına sahiptir. Küresel en büyük mobil mesajlaşma uygulamaları ve sosyal ağlar arasında yer alan Çin merkezli ücretsiz mesajlaşma uygulamalarından birisi olan WeChat uygulaması İOS ve Android tabanlı cihazlarda kullanılan bir yazılımdır. WeChat 2011 yılı ocak ayında Teng Xun tarafından yayınlanmıştır. 200 den fazla ülkede aktif kullanıcısı olan uygulamanın 2016 verilerine göre yaklaşık 700 milyon aktif kullanıcısı bulunmaktadır ve 17 dilde kullanılabilmektedir. Yeni ve güçlü bir mobil iletişim aracı olan WeChat ses, görüntü, fotoğraf ve metin mesajları göndermeyi desteklemektedir (www.wikipedia.com, erişim tarihi: 05.03.2017).

\section{WeChat Özellikleri:}

- Çoklu platform desteği

- Sesli notlar, resimler, videolar, konum bilgisi ve çok daha fazlasını paylaşma

- Grup mesajlaşma özelliği/ grup üyeleri arasında canlı sohbet

- $\quad$ HD kalitesinde ücretsiz görüntülü arama

- Mesaj geçmişini çevrimdışı olarak görüntüleme

- Reklamsiz

- Kişisel fotoğraf albümü oluşturma ve paylaşma

- QR kod tarama

- Telefon kişilerini otomatik eşleştirme 
Yazıcı, T., Tuerxun, X. (2017). Dijital kamusal alanda grup iletişimi: WeChat örneği. International Journal of Social Sciences and Education Research, 3(3), 966-980.

- Telefon numaranıza özel kayıt işlemi

- Web'de sohbet özelliği

- Çoklu dil desteği

- Beğenen link deposu yapma

- Ücretsiz telefon araması yapma, kameralı konuşma

- Sallama ve arkadaş bulma özelliği

- Etraftakini bul özelliği ile yüz metre civarında WeChat kullananları bulma

- Ücretsiz kullanım

\section{Araştırma}

\subsection{Araştırmanin amacl ve önemi}

Çalışmanın amacı Çin'de çok yaygın kullanılan sosyal ağ uygulaması WeChat iletişim platformunda grup iletişiminin önemini ve kullanım amaçlarını inceleyerek, yeni medyanın yeni bir kamusal alan inşa etme potansiyeli doğrutusunda WeChat grup iletişiminin dijital kamusal alanın bir parçası olup olmadığını tartışmaktır.

Çin merkezli WeChat iletişim platformunda grup iletişiminin çok yaygın kullanıldığı ve grupların belli konular üzerinde toplanarak çeşitli tartışma, öneri ve paylaşımlarla diğer insanlara bilgi sağlamaya yardımcı olmakta, bazı gruplar insanların ihtiyaçlarını karşılamak amacıyla kurulmaktadır. Grup kullanım özelliklerinde sesli mesaj ile sohbet yapılmaktadır. İnsanlar grup iletişimi ile çeşitli organizasyonlar düzenleyerek bunu açık alanlarda gerçekleştirmektedir. Grup iletişimi WeChat kullanıcıları için çok önemlidir ve digital ortamda oluşturulan grup iletişiminde kullanıcılar arasında dijital kamusal alan oluşturması doğrultusunda bir çalışma gerçekleştirilmiştir.

\subsection{Araştırmanın yöntemi}

Çalışma sosyal platformlardan biri olan WeChat uygulamasının dijital kamusal alanda grup iletişimini anlamak amacıyla yürütülen nitel araştırma yöntemlerinin kullanıldığı fenomonolojik bir araştırmadır. Bu yaklaşımda bireylerin daha çok dijital kamusal alanda grup iletişimi ve bu sürecin bireylerdeki etkilerini ve davranışlarını anlamak açısından uygun olduğu görülmüştür. Bu çalışmanın evreni 16-66 yaş arasındaki bu platformda deneyime sahip kulllanıcılar olarak belirlenmiştir.

Çalışmada veri araştırma yöntemi olarak yarı yapılandırılmış görüşme formları kullanılmıştır. Katılımcılar araştırmaların gizliliği esasına uyularak isimleri verilmemiş ve katılımcılar K1, K2, K3 gibi kodlarla tanımlanmıştır.

Görüşme Formu: "Dijital Kamusal Alanda Grup İletişimi" şeklinde belirlenmiş ve bu yöntem esas alınmıştır. Görüşme öncesinde katılımcılara dijital kamusal alan nedir diye kısa açık bir tanım yapılmıştır. Görüşme formu iki başlık altında yer alan sorulardan ve bu doğrultuda ortaya çıkan görüşlerden oluşmaktadır. Görüşme formlarında yer alan değerlendirme alanları şu şekildedir:

\section{A-) Dijital kamusal alana iliş̧kin görüşler}

1) Dijital kamusal alan faaliyetine katılmak bireyleri mutlu eder.

2) Dijital kamusal alan yalnızlaşmanın önüne geçer.

3) Dijital kamusal alan yeni ilişki ağları kurmaya yardımcı olur. 
Yazıc1, T., Tuerxun, X. (2017). Group communication at digital public space: WeChat sample. International Journal of Social Sciences and Education Research, 3(3), 966-980.

\section{B-) Dijital kamusal alanda grup iletişimine ilişkin görüşler}

1) Dijital kamusal alan sunduğu ortamda kullanıcıyı yalnızlaştırır

2) Dijital kamusal alan katılımcının katılım seviyesini arttırır.

3) Dijital kamusal alan toplumsal katılımı sağlar.

4) Dijital kamusal alanda grup iletişimi performansını artırır.

5) Dijital kamusal alan grup iletişiminde yeni medya algısıyla geleneksel grup iletişim algısını degiştirerek yalnızlaştırır.

\subsection{Araştırmanın bulguları}

\subsubsection{Katılımcıların demografik özellikleri ve görüssleri}

Tablo 1. Katılımc1ların demografik özellikleri

\begin{tabular}{|l|l|l|l|l|l|}
\hline Katılımcı & Cinsiyet & Yaş & $\begin{array}{l}\text { Medeni Du- } \\
\text { rum }\end{array}$ & Ĕgitim & Meslek \\
\hline K1 & Erkek & 26 & Evli & Lisans & Diş doktoru \\
\hline K2 & Erkek & 66 & Evli & Yüksek Lisans & Emekli Öğretmen \\
\hline K3 & Kadın & 34 & Evli & Yüksek Lisans & Öğretmen \\
\hline K4 & Kadın & 30 & Evli & Yüksek Lisans & Öğrenci \\
\hline K5 & Kadın & 31 & Evli & Lisans & Özel Sektör \\
\hline K6 & Kadın & 16 & Bekar & Lise & Öğrenci \\
\hline K7 & Erkek & 41 & Evli & Lisans & Serbest Meslek \\
\hline K8 & Kadın & 29 & Bekar & Lisans & Öğrenci \\
\hline K9 & Erkek & 33 & Evli & Lisans & Uzman \\
\hline K10 & Erkek & 26 & Bekar & Lisans & Serbest Meslek \\
\hline
\end{tabular}

Çalışmada 5 kadın ve 5 erkek olmak üzere toplamda 10 katılımcı ile görüşme gerçekleştirilmiştir. 16-66 yaş aralığında yer alan katılımcıların 7'si evli, 3'ü bekârdır. Eğitim düzeylerine göre değerlendirildiğinde 1 lise mezunu, 6 lisans ve 3 yüksek lisans düzeyinde katılımcı yer almaktadır. Meslek özelliklerine göre 1 diş doktoru, 2 öğretmen, 3 öğrenci, 1 özel sektör ve 2 serbest meslek çalışanı bulunmaktadır.

Tablo 2. Dijital kamusal alana ilişkin görüşler

\begin{tabular}{|c|l|l|l|}
\hline \multicolumn{3}{|c|}{ Dijital kamusal alana ilişkin görüşler } \\
\hline $\begin{array}{c}\text { Katılı } \\
\text { mcı }\end{array}$ & $\begin{array}{l}\text { Dijital kamusal alan faali- } \\
\text { yetine katılmak bireyleri } \\
\text { mutlu eder. }\end{array}$ & $\begin{array}{l}\text { Dijital kamusal alan yal- } \\
\text { nızlaşmanın önüne geçer. }\end{array}$ & $\begin{array}{l}\text { Dijital kamusal alan yeni } \\
\text { ilişki ağları kurmaya } \\
\text { yardımcı olur. }\end{array}$ \\
\hline K1 & $\begin{array}{l}\text { Evet mutlu eder. saniyeler } \\
\text { içinde istediğimiz kişiyle } \\
\text { iletişim kurarız. }\end{array}$ & $\begin{array}{l}\text { Evet, dijital kamusal alanda } \\
\text { birçok kişi ile anında ko- } \\
\text { nusur, tartışır, meşgul } \\
\text { oluruz, sosyalleşiriz. }\end{array}$ & $\begin{array}{l}\text { Evet, ben kamusal alanda } \\
\text { akrabalarımı ve mes- } \\
\text { lektaşlarımı bir araya toplay- } \\
\text { abilirim ve burdan birbirimizi } \\
\text { buluruz. }\end{array}$ \\
\hline K2 & $\begin{array}{l}\text { Mutlu edebilir ama sanal bir } \\
\text { mutluluktur. }\end{array}$ & $\begin{array}{l}\text { Hayır insanı daha da yalnız } \\
\text { k1lar. }\end{array}$ & $\begin{array}{l}\text { Sanal ortamda kurulan } \\
\text { ilişkiler gerçek degildir. } \\
\text { Ilişkin ne kadar iyi olabilir } \\
\text { ki? }\end{array}$ \\
\hline
\end{tabular}


Yazıcı, T., Tuerxun, X. (2017). Dijital kamusal alanda grup iletişimi: WeChat örneği. International Journal of Social Sciences and Education Research, 3(3), 966-980.

Tablo 2. Dijital kamusal alana ilişkin görüşler (Devam)

\begin{tabular}{|c|c|c|c|}
\hline \multicolumn{4}{|c|}{ Dijital kamusal alana ilişkin görüşler } \\
\hline $\begin{array}{c}\text { Katılı } \\
\text { mcı }\end{array}$ & $\begin{array}{l}\text { Dijital kamusal alan faali- } \\
\text { yetine katılmak bireyleri } \\
\text { mutlu eder. }\end{array}$ & $\begin{array}{l}\text { Dijital kamusal alan yal- } \\
\text { nızlaşmanın önüne geçer. }\end{array}$ & $\begin{array}{l}\text { Dijital kamusal } \\
\text { ilişki ağan yeni } \\
\text { yardımcı olur. }\end{array}$ \\
\hline K3 & $\begin{array}{l}\text { Evet mutlu eder. Sanal da } \\
\text { olsa paylasımdır. Ayrıca her } \\
\text { yerde her zaman katıla- } \\
\text { biliriz. }\end{array}$ & Bence yalnızlaşmayı arttırır. & $\begin{array}{l}\text { Yardımcı olabilir ama bu } \\
\text { ilişkiler yüzeysel kalır. }\end{array}$ \\
\hline K4 & $\begin{array}{l}\text { Evet mutlu eder. Çünkü di- } \\
\text { jital kamusal alan faali- } \\
\text { yetlerinde herkes kendi } \\
\text { mesleğine hobisine ve ken- } \\
\text { dini en yakın hisettiği gru- } \\
\text { plara katılabilir, ilişkilerini } \\
\text { uzun süreler sürdürebilir, } \\
\text { bilgi edinebilir, sevinç, } \\
\text { tecrübe, paylaşabilir. }\end{array}$ & $\begin{array}{l}\text { Evet, bence herkes sanal or- } \\
\text { tamda çok sosyalleşmiş ama } \\
\text { gerçek hayatta birer yalnız } \\
\text { insandır. }\end{array}$ & $\begin{array}{l}\text { Evet katılıyorum, ben bu di- } \\
\text { jital kamusal alanda kendi } \\
\text { eski arkadaşlarımı, } \\
\text { tanıdıklarımı buldum, yeni } \\
\text { insanlarla tanıştım, aynı ilgi } \\
\text { alanını paylaşarak burdan } \\
\text { dost ve tanıdık edindik. }\end{array}$ \\
\hline K5 & $\begin{array}{l}\text { Duruma göre değişebilir, } \\
\text { mesala uzak mesafedeki } \\
\text { ilişki anlamında mutluluk } \\
\text { verici. Mutsuz yönüde } \\
\text { herşeyi paylaştığımı için } \\
\text { gerçek özlemeyi ve kıymet } \\
\text { vermeyi unutuyoruz. }\end{array}$ & $\begin{array}{l}\text { Yanlızlaşma bence göreceli } \\
\text { bir kavram, kimi digital } \\
\text { alanda kendini sosyalleştiri- } \\
\text { yor, arkadaşlık ediniyor, iyi } \\
\text { ortam kuruyor, kimi kendini } \\
\text { kaybediyor. }\end{array}$ & $\begin{array}{l}\text { Yeni ilişki ağları kurmaya } \\
\text { yardımcı olur tabiki de çünkü } \\
\text { artık insanlara ulaşmak çok } \\
\text { kolay, iş arıyorsunuz, bir } \\
\text { oyun arkadaşı istiyorsunuz } \\
\text { ister istemez bir ağ kurmuş } \\
\text { oluyorsunuz. }\end{array}$ \\
\hline K6 & Evet çok mutlu eder. & 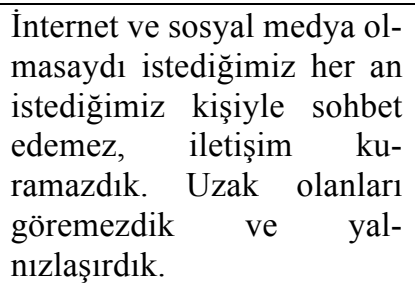 & $\begin{array}{l}\text { Kesinlikle katıliyorum. Aynı } \\
\text { gruplarda yazınca zev- } \\
\text { klerimizin de aynı olduğunu } \\
\text { fark edip konuşmaya } \\
\text { başladık. }\end{array}$ \\
\hline K7 & $\begin{array}{l}\text { Mutlu eder, ben burdan her } \\
\text { türlü bilgiden yararlana- } \\
\text { bilirim }\end{array}$ & $\begin{array}{l}\text { İnsan ile insan arasındaki } \\
\text { gerçek mesafeyi yok eder } \\
\text { sanal kalır, gerçekçi degil o } \\
\text { yüzden yalnızlaştırır. }\end{array}$ & $\begin{array}{l}\text { Katılıyorum. sanal ortamda } \\
\text { aynı ilgi alanındakiler birbi- } \\
\text { rini bulurlar. }\end{array}$ \\
\hline K8 & $\begin{array}{l}\text { Evet eder ama geçici bir } \\
\text { süre. }\end{array}$ & $\begin{array}{l}\text { Sanal ortam oldugu için } \\
\text { gerçekliği yoktur yanlızlığın } \\
\text { önüne geçmez. }\end{array}$ & $\begin{array}{l}\text { Evet yeni ilişki ağları } \\
\text { kurmaya yardımcı olur ama } \\
\text { sanal ortam olduğu için pek } \\
\text { sağlıklı ilişkiler oluşmaz ve } \\
\text { kısa süreli olur. }\end{array}$ \\
\hline K9 & $\begin{array}{l}\text { Evet. Bilgi paylaşmak için } \\
\text { geniş bir çevreye ulaşılıyor. }\end{array}$ & $\begin{array}{l}\text { Evet. Farklı insanlarla farklı } \\
\text { konularda } \\
\text { geçmemizi sağlar. }\end{array}$ & $\begin{array}{l}\text { Evet. Farklı insanlarla yeni } \\
\text { ilişkiler de kurulur. }\end{array}$ \\
\hline K10 & $\begin{array}{l}\text { Evet mutlu eder çünkü in- } \\
\text { sanlar rahat bir şekilde } \\
\text { iletişim kurabilirler. }\end{array}$ & $\begin{array}{l}\text { Evet önüne geçer. İnsanlar } \\
\text { dilediği saatte iletişim ku- } \\
\text { rabilirler. }\end{array}$ & $\begin{array}{l}\text { Evet yeni ilişkiler ku- } \\
\text { rabilirler. Bir çok insan bu } \\
\text { alanda aktif. }\end{array}$ \\
\hline
\end{tabular}


Yazıc1, T., Tuerxun, X. (2017). Group communication at digital public space: WeChat sample. International Journal of Social Sciences and Education Research, 3(3), 966-980.

Tablo 3. Dijital kamusal alanda grup iletişimine ilişkin görüşler

\begin{tabular}{|c|c|c|c|c|c|}
\hline \multicolumn{6}{|c|}{ Dijital kamusal alanda grup iletişimine ilişkin görüşler } \\
\hline $\begin{array}{l}\text { Katılı } \\
\text { meı }\end{array}$ & $\begin{array}{l}\text { Dijital kamusal } \\
\text { alan sunduğu } \\
\text { ortamda } \\
\text { kullanıcıyı yal- } \\
\text { nızlaştırır. }\end{array}$ & $\begin{array}{l}\text { Dijital kamusal } \\
\text { alan } \\
\text { katılımeının } \\
\text { katılım se- } \\
\text { viyesini arttırır. }\end{array}$ & $\begin{array}{l}\text { Dijital kamusal } \\
\text { alan toplumsal } \\
\text { katılımı sağlar. }\end{array}$ & $\begin{array}{l}\text { Dijital kamu- } \\
\text { sal alan grup } \\
\text { iletişimi per- } \\
\text { formansını } \\
\text { arttırır. }\end{array}$ & $\begin{array}{l}\text { Dijital kamusal } \\
\text { alan grup } \\
\text { iletişiminde } \\
\text { yeni medya al- } \\
\text { gısıyla gele- } \\
\text { neksel grup } \\
\text { iletişim algısını } \\
\text { degiştirerek } \\
\text { yalnızlaştırır. }\end{array}$ \\
\hline K1 & $\begin{array}{l}\text { Evet, sanal or- } \\
\text { tam gerçek or- } \\
\text { tamdan farklıdır. }\end{array}$ & $\begin{array}{l}\text { Evet. Sanal or- } \\
\text { tamda bir çok } \\
\text { bilgi ediniliyor, } \\
\text { bu bir çok in- } \\
\text { sanın katıllımın } \\
\text { sağlar. }\end{array}$ & $\begin{array}{l}\text { Evet sağlar. Ben } \\
\text { sanal ortamda } \\
\text { birçok arka- } \\
\text { daşılmla grup } \\
\text { iletisimi } \\
\text { sürdürüyorum, } \\
\text { onlarla dişarıda } \\
\text { sürekli buluşuy- } \\
\text { orum. }\end{array}$ & $\begin{array}{l}\text { Evet ben diş } \\
\text { doktoru olarak } \\
\text { diş doktorları } \\
\text { grubuna } \\
\text { katıldım mes- } \\
\text { leğimizle ilgili } \\
\text { birçok bilgi } \\
\text { paylaşıyoruz }\end{array}$ & $\begin{array}{l}\text { Evet bence } \\
\text { hiçbir şey somut } \\
\text { olmaya yetmez. }\end{array}$ \\
\hline K2 & $\begin{array}{l}\text { Evet yal- } \\
\text { nızlaştırır. İnsan } \\
\text { dişarıya çıkıp } \\
\text { sosyalleşmediği } \\
\text { sürece yalnızdır. }\end{array}$ & $\begin{array}{lrr}\text { İnsan } & \text { hiç } & \text { olma- } \\
\text { dığ } 1 \text { bir } & \text { kişi } \\
\text { olarak } & \text { katılır } \\
\text { gruplara. } & \end{array}$ & $\begin{array}{l}\text { Evet. Toplum } \\
\text { sosyal medyada } \\
\text { daha kolay bir } \\
\text { araya gelir. Daha } \\
\text { çok insana daha } \\
\text { kolay ulaşıla- } \\
\text { bilir. }\end{array}$ & $\begin{array}{l}\text { Grup icinde } \\
\text { kisi dijital or- } \\
\text { tamda daha ak- } \\
\text { tiftir çünkü yüz } \\
\text { yüzeyken } \\
\text { söylemekten } \\
\text { çekindiği, } \\
\text { birçok seyi } \\
\text { daha rahat ve } \\
\text { kolay soyleye- } \\
\text { bilir. }\end{array}$ & $\begin{array}{l}\text { Tabii ki } \\
\text { degiştirir ve } \\
\text { kişiyi yal- } \\
\text { nizlaştırır. Gülen } \\
\text { yüz simgeleri } \\
\text { gerçek } \\
\text { kahkahaların } \\
\begin{array}{l}\text { yerini tutabilir } \\
\text { mi? }\end{array}\end{array}$ \\
\hline K3 & $\begin{array}{lr}\text { Evet } & \text { yal- } \\
\text { nızlaştırır. } & \text { Bi- } \\
\text { reyseldir, grup } \\
\text { halinde iletişim } \\
\text { olsa da yal- } \\
\text { nızsındır. }\end{array}$ & $\begin{array}{l}\text { Evet katılım se- } \\
\text { viyesini arttırır } \\
\text { çünkü yüz yüze } \\
\text { olmayınca kişi } \\
\text { daha özgüvenli } \\
\text { ve aktif olur. }\end{array}$ & $\begin{array}{l}\text { Evet. Yüz yüze } \\
\text { ve hizlı bir } \\
\text { şekilde örgütlen- } \\
\text { melerde fazla } \\
\text { kişiye ulaşmak } \\
\text { pek kolay } \\
\text { değildir. }\end{array}$ & $\begin{array}{l}\text { Artıtırır ama } \\
\text { yüzeysel bazen } \\
\text { yapmaciktır. }\end{array}$ & $\begin{array}{l}\text { Kensinlikle } \\
\text { katılıyorum. Ge- } \\
\text { leneksel samimi } \\
\text { ve çoğulcuydu, } \\
\text { dijital soğuk ve } \\
\text { bireyseldir. }\end{array}$ \\
\hline K4 & $\begin{array}{lr}\text { Evet, eskisi gibi } \\
\text { insanlar kamusal } \\
\text { alanda top- } \\
\text { lanmaz oldu, } \\
\text { arkadaşlar sanal } \\
\text { ortamda çok } \\
\text { ama yanımızda } \\
\text { yoklar. }\end{array}$ & $\begin{array}{l}\text { Evet } \\
\text { kat1lyyorum. } \\
\text { WeChat ile in- } \\
\text { sanlar olup } \\
\text { bitenlerden, } \\
\text { buluşma- } \\
\text { lardanorgani- } \\
\text { zasyonlardan, } \\
\text { düğün davetleri } \\
\text { ve bir çok davet- } \\
\text { ten haberdar ol- } \\
\text { uyor. }\end{array}$ & $\begin{array}{l}\text { Toplumsal } \\
\text { katılımı sağlar. } \\
\text { Ben bir çok } \\
\text { gruba üye oldum } \\
\text { ve bazı organi- } \\
\text { zasyonlara } \\
\text { katıldım dağ } \\
\text { tırmanma grub- } \\
\text { unu faaliyetine, } \\
\text { yabancı öğren- } \\
\text { cilerin şölenine. }\end{array}$ & $\begin{array}{l}\text { Evet } \\
\text { katıliyorum, } \\
\text { birçok insan } \\
\text { kendi ilgi } \\
\text { alanında, arka- } \\
\text { daş akraba, } \\
\text { meslek ve ho- } \\
\text { bilerine göre } \\
\text { farklı gruplara } \\
\text { üye oldular ve } \\
\text { paylaşımlarda } \\
\text { bulundular. }\end{array}$ & $\begin{array}{lr}\text { Evet } & \text { yal- } \\
\text { nızlaştırır, beden } \\
\text { diliyle bir in- } \\
\text { sanın karekterini } \\
\text { hislerini anlaya- } \\
\text { biliriz ama sanal } \\
\text { ortamda gerçek } \\
\text { ifadelerde sahte } \\
\text { simgeler ile } \\
\text { ifade ederek } \\
\text { farkli bir } \\
\text { düşünce yaratır. }\end{array}$ \\
\hline
\end{tabular}


Yazıcı, T., Tuerxun, X. (2017). Dijital kamusal alanda grup iletişimi: WeChat örneği. International Journal of Social Sciences and Education Research, 3(3), 966-980.

Tablo 3. Dijital kamusal alanda grup iletişimine ilişkin görüşler (Devam)

\begin{tabular}{|c|c|c|c|c|c|}
\hline \multicolumn{6}{|c|}{ Dijital kamusal alanda grup iletişimine ilișkin görüşler } \\
\hline $\begin{array}{l}\text { Katılı } \\
\text { mcı }\end{array}$ & $\begin{array}{l}\text { Dijital kamusal } \\
\text { alan sunduğu } \\
\text { ortamda } \\
\text { kullanıcıyı yal- } \\
\text { nızlaştırır. }\end{array}$ & $\begin{array}{l}\text { Dijital kamusal } \\
\text { alan } \\
\text { katılımcının } \\
\text { katılım se- } \\
\text { viyesini arttırır. }\end{array}$ & $\begin{array}{l}\text { Dijital kamusal } \\
\text { alan toplumsal } \\
\text { katılımı sağlar. }\end{array}$ & $\begin{array}{l}\text { Dijital kamu- } \\
\text { sal alan grup } \\
\text { iletişimi per- } \\
\text { formansını } \\
\text { arttırır. }\end{array}$ & $\begin{array}{l}\text { Dijital kamusal } \\
\text { alan grup } \\
\text { iletişiminde } \\
\text { yeni medya al- } \\
\text { gısıyla gele- } \\
\text { neksel grup } \\
\text { iletişim algısını } \\
\text { degiştirerek } \\
\text { yalnızlaştırır. }\end{array}$ \\
\hline K5 & $\begin{array}{l}\text { Grup içinde aktif } \\
\text { bir kulanımda } \\
\text { olursam yalnız } \\
\text { hissetmem ama } \\
\text { hiçbir fikre } \\
\text { sosyal etkinliğe } \\
\text { katılmadığım sü- } \\
\text { rece tabiki yal- } \\
\text { nız hissederim. }\end{array}$ & $\begin{array}{l}\text { Katılım se- } \\
\text { viyesini artırır. }\end{array}$ & $\begin{array}{l}\text { Toplumsal } \\
\text { katılım } \\
\text { keskinlikle } \\
\text { sağlar, bir hasta } \\
\text { çocuk vardı kim- } \\
\text { senin haberi yok, } \\
\text { digital ortamda } \\
\text { haberdar oluruz } \\
\text { yardım ederiz. }\end{array}$ & $\begin{array}{l}\text { Evet grup } \\
\text { iletişim perfor- } \\
\text { mansı artırır. }\end{array}$ & $\begin{array}{l}\text { Tutamaz ama bu } \\
\text { durum artık } \\
\text { sinmiş durumda } \\
\text { hayatımıza. An- } \\
\text { neme bir çiçek } \\
\text { alamasamda bir } \\
\text { çicek simgesiyle } \\
\text { mutlu edebili- } \\
\text { yorum. }\end{array}$ \\
\hline K6 & $\begin{array}{l}\text { Hayır yal- } \\
\text { nızlaştırmaz. } \\
\text { Grup içinde } \\
\text { olduğunuz için } \\
\text { daha sosyal } \\
\text { olursunuz. Hep- } \\
\text { siyle bir şeyler } \\
\text { paylaşıyorsunuz } \\
\text { bu sosyalliktir. }\end{array}$ & $\begin{array}{l}\text { Tabiki arttırır. } \\
\text { Yüz yüzeyken } \\
\text { söyleyemedigim } \\
\text { birçok seyi inter- } \\
\text { netten söyleye- } \\
\text { biliyorum. } \\
\text { Boylece de } \\
\text { herşeye daha ko- } \\
\text { lay katılıp dahil } \\
\text { olabiliyorum. }\end{array}$ & $\begin{array}{l}\text { Toplumsal } \\
\text { katılım internet } \\
\text { sayesinde çok } \\
\text { daha fazlalaştı } \\
\text { ve kolaylaştı. } \\
\text { Haberler hemen } \\
\text { yayılabiliyor ve } \\
\text { insanlar yardım } \\
\text { konularında } \\
\text { hemen katılımda } \\
\text { bulunabiliyor. }\end{array}$ & $\begin{array}{lr}\text { Evet } & \text { arttırır. } \\
\text { Grup } & \text { iletişimi } \\
\text { daha } & \text { ko- } \\
\text { laylaşır. } & \end{array}$ & $\begin{array}{l}\text { Hayır } \\
\text { katılmıyorum. } \\
\text { Geleneksel olan } \\
\text { iletişim belki } \\
\text { daha gerçek ve } \\
\text { daha kalıcı } \\
\text { olabilir ama o } \\
\text { zaman insanlar } \\
\text { daha yalnızdi. } \\
\text { Şimdi daha } \\
\text { sosyal ve aktif. } \\
\text { Yaşl kişiler in- } \\
\text { ternet kullanıp } \\
\text { birçok şeyden } \\
\text { haberdar olabili- } \\
\text { yor, etkinliklere } \\
\text { katılabiliyor. } \\
\text { Yani aktif ve } \\
\text { sosyal oluyor. }\end{array}$ \\
\hline K7 & $\begin{array}{l}\text { Katılmıyorum, } \\
\text { çünkü orda da } \\
\text { her türlü insan } \\
\text { var, sürekli } \\
\text { iletişim içeris- } \\
\text { indeyiz ko- } \\
\begin{array}{l}\text { nuşuruz, hatta } \\
\text { oyun oynarız. }\end{array}\end{array}$ & $\begin{array}{l}\text { Katılmıyorum. } \\
\text { Bence bireysel } \\
\text { katılımı za- } \\
\text { yıflaştırır, aktif } \\
\text { insan her yerde } \\
\text { aktiftir. }\end{array}$ & $\begin{array}{l}\text { Kat1liyorum. } \\
\text { Sanal ortamda } \\
\text { her topluma } \\
\text { katılır fikirlerini } \\
\text { söyler. }\end{array}$ & $\begin{array}{l}\text { Katıliyorum } \\
\text { ben sanal or- } \\
\text { tamda daha } \\
\text { çok konuşu- } \\
\text { rum çekinmem } \\
\text {,çünkü } \\
\text { görünmüyoruz } \\
\text {. }\end{array}$ & $\begin{array}{l}\text { Kesinlikle } \\
\text { katılıyorum. Ge- } \\
\text { leneksel bire bir } \\
\text { ve gerçekci } \\
\text { canlıdır. Dijital } \\
\text { ise soyut ve } \\
\text { uzaktır. }\end{array}$ \\
\hline K8 & $\begin{array}{l}\text { Yalnızlaştırır } \\
\text { çünkü } \\
\text { sosyalleşme } \\
\text { olmaz. }\end{array}$ & $\begin{array}{l}\text { Arttırabilir } \\
\text { çünkü sanal or- } \\
\text { tamda gerçek } \\
\text { hayata göre daha } \\
\text { kolay olur. }\end{array}$ & $\begin{array}{l}\text { Evet daha hızlı } \\
\text { şekilde oluşur ve } \\
\text { çok sayıda } \\
\text { katılım } \\
\text { bağlana- } \\
\text { bilir. }\end{array}$ & $\begin{array}{l}\text { Katılıyorum } \\
\text { arttırır kışı } \\
\text { daha rahat bır } \\
\text { şekılde kendını } \\
\text { ifade edebılır. }\end{array}$ & $\begin{array}{l}\text { Evet geleneksel- } \\
\text { likten uzaklaşır } \\
\text { ve değiştirir. }\end{array}$ \\
\hline
\end{tabular}


Yazıc1, T., Tuerxun, X. (2017). Group communication at digital public space: WeChat sample. International Journal of Social Sciences and Education Research, 3(3), 966-980.

Tablo 3. Dijital kamusal alanda grup iletişimine ilişkin görüşler (Devam)

\begin{tabular}{|c|c|c|c|c|c|}
\hline \multicolumn{6}{|c|}{ Dijital kamusal alanda grup iletişimine ilişkin görüsşler } \\
\hline $\begin{array}{l}\text { Katılı } \\
\text { mcı }\end{array}$ & $\begin{array}{l}\text { Dijital kamusal } \\
\text { alan sunduğu } \\
\text { ortamda } \\
\text { kullanıcıyı yal- } \\
\text { nızlaştırır. }\end{array}$ & $\begin{array}{l}\text { Dijital kamusal } \\
\text { alan } \\
\text { katılımcının } \\
\text { katılım se- } \\
\text { viyesini arttırır. }\end{array}$ & $\begin{array}{l}\text { Dijital kamusal } \\
\text { alan toplumsal } \\
\text { katılımı sağlar. }\end{array}$ & $\begin{array}{l}\text { Dijital kamu- } \\
\text { sal alan grup } \\
\text { iletişimi per- } \\
\text { formansını } \\
\text { arttırır. }\end{array}$ & $\begin{array}{l}\text { Dijital kamusal } \\
\text { alan grup } \\
\text { iletişiminde } \\
\text { yeni medya al- } \\
\text { gısıyla gele- } \\
\text { neksel grup } \\
\text { iletişim algısını } \\
\text { degiştirerek } \\
\text { yalnızlaştırır. }\end{array}$ \\
\hline K9 & $\begin{array}{lr}\text { Hayır. } & \text { İnsan } \\
\text { sosyal } & \text { bir } \\
\text { canlıdır } & \text { dijital } \\
\text { olarak bile olsa } \\
\text { kurduğu } & \text { ilişskiyi } \\
\text { sosyal } & \text { alana } \\
\text { taşır. } & \end{array}$ & $\begin{array}{l}\text { Evet. Çok fazla } \\
\text { insana katılım } \\
\text { olanağ1 sağlar. }\end{array}$ & $\begin{array}{l}\text { Çok fazla insana } \\
\text { katılım olanag1 } \\
\text { sağladığı için } \\
\text { performansı da } \\
\text { yüksek olur. }\end{array}$ & $\begin{array}{l}\text { evet, bır cok } \\
\text { farklı grupla } \\
\text { 1letışıme } \\
\text { geçılen alan } \\
\text { grupların } \\
\text { 1letışım perfor- } \\
\text { manslarını art- } \\
\text { tırır. }\end{array}$ & $\begin{array}{l}\text { Evet insanlar bi- } \\
\text { reysel olarak } \\
\text { yalnız kal- } \\
\text { miyorken ken- } \\
\text { dini gruplara } \\
\text { katıldığında } \\
\text { farklı gruplarla } \\
\text { iletişime kapalı } \\
\text { hale gelebilirler. }\end{array}$ \\
\hline K10 & $\begin{array}{l}\text { Hayır } \\
\text { yanlızlaştırmaz } \\
\text { aksine birçok in- } \\
\text { sanla tanışıp } \\
\text { kaynaşmasını } \\
\text { sağlar. }\end{array}$ & 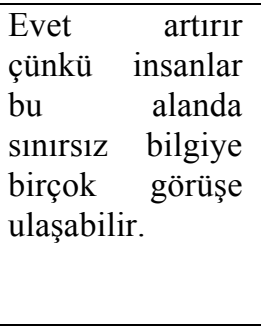 & $\begin{array}{l}\text { Evet çünkü in- } \\
\text { sanların ortak } \\
\text { paydada } \\
\text { buluşabileceği } \\
\text { bir alandır. }\end{array}$ & $\begin{array}{l}\text { Evet bir çok in- } \\
\text { sanla iletişim } \\
\text { halinde } \\
\text { olunduğu için } \\
\text { insanların } \\
\text { iletişim perfor- } \\
\text { mansı artar. }\end{array}$ & $\begin{array}{l}\text { Hayır } \\
\text { nızlaştırmaz } \\
\text { çünkü bu alan } \\
\text { hem bireysel } \\
\text { hem grup } \\
\text { iletişimi için } \\
\text { oldukça müsait } \\
\text { bir alandır. }\end{array}$ \\
\hline
\end{tabular}

\subsubsection{Dijital kamusal alana ilişkin görüşler}

\section{1) Dijital kamusal alan faaliyetine katılmak bireyleri mutlu eder.}

Tüm katılımcılar bireyleri mutlu ettiğini ifade etmektedir. İstenilen kişilerle iletişim kurmanın, her yerde ve her zaman katılımda bulunmanın, kendi mesleklerine ve ilgi alanlarına yönelik gruplara katılım olanağının olmasının ve paylaşımda bulunabilmenin ve her türlü bilgiden faydalanmanın bireyleri mutlu ettiğini belirtmektedirler. Katılımcılardan 1 tanesi yaşanılan bu mutluluğun sanal bir mutluluk olduğunu, diğer bir katılımcı uzaklık ve yakınlık durumuna göre değişebileceğini ve yine 1 katılımcı da bu mutluluğun geçici bir mutluluk olduğunu belirtmektedir.

2) Dijital kamusal alan yalnızlaşmanın önüne geçer.

Katılımcılardan 4'ü yalnızlaşmanın önüne geçtiğini, 5 katılımcı ise aslında insanları daha çok yalnızlaştırdığını, 1 katılımcı ise yalnızlaşmanın göreceli bir kavram olduğunu ifade etmektedir. Yalnızlaşmanın önüne geçtiğini belirten katılımcılar bu durumu farklı alanlarda birçok insanla istedikleri zamanda iletişim kurma, vakit geçirme, meşgul olma ve sohbet etme özellikleri ile ilişkilendirmektedir. Olumsuz görüş bildiren katılımcılar yalnızlaşmayı arttırdığı ve sanal ortamın gerçekçi olmadığı için gerçek hayatta insanların yalnız olduğunu belirtmektedir.

\section{3) Dijital kamusal alan yeni ilişki ağları kurmaya yardımcı olur.}

8 katılımcı dijital kamusal alanın yeni ilişki ağları kurmaya yardımcı olduğunu, 1 katılımcı sanal ortamda kurulan ilişkilerin gerçekçi olmadığını ve 1 katılımcı da ilişkilerin yüzeysel 
Yazıcı, T., Tuerxun, X. (2017). Dijital kamusal alanda grup iletişimi: WeChat örneği. International Journal of Social Sciences and Education Research, 3(3), 966-980.

kaldığını belirtmektedir. Olumlu görüş bildiren katılımcılar ardaşlar, akrabalar ve meslektaşlar ile bir arada olduklarını, ilgi alanlarına yönelik yeni insanlarla tanıştıklarını ve iletişime devam ettiklerini belirtmektedir. Olumsuz görüş bildiren katılımcı ise ilişkilerin gerçek olmadığını, sanal ortam olduğu için sağlısız ve kısa süreli ilişkiler olduğunu ifade etmektedir.

\subsubsection{Dijital kamusal alanda grup iletişimine ilişskin görüşler}

\section{1) Dijital kamusal alan sunduğu ortamda kullanıcıyı yalnızlaştırır.}

5 katılımcı dijital kamusal alanın bireyi yalnızlaştırdığını, 5 katılımcı ise yalnızlaştırmadığını belirtmektedir. Yalnızlaştırdığını belirten katılımcılar gerçek hayatta sosyallaşme olmaması ve sanal bir ortam olmasından dolayı bireyin aslında yalnız olduğunu ifade etmektedir. Diğer katılımcılar grup içinde aktif kullanım, paylaşım ve iletişim olması durumunda ve yeni insanlarla tanışıldığında bireyi yalnızlaştırmadığını belirtmektedir.

\section{2) Dijital kamusal alan katılımcinın katılım seviyesini arttırır.}

9 katılımcı katılım seviyesini arttırdığını, 1 katılımcı ise katılımı zayıflattığını belirtmektedir. Olumlu görüş bildiren katılımcılar kişilerin yüzyüze iletişime göre daha kolay iletişim kurabildiklerini, bilgi alışverişinde bulunduklarını, çeşitli sosyal aktivitelere katıldıklarını, gerçek hayata göre daha kolay ve daha fazla katılım inkanı sağladığını belirtmektedir. Olumsuz görüş bildiren katılımcı ise, bireysel katılımı zayıtlattığını, aktif olanların her yerde aynı özelliği gösterdiğini ifade etmektedir.

\section{3) Dijital kamusal alan toplumsal katılımı să̆lar.}

Tüm katılımcılar dijital kamusal alanın toplumsal katılımı sağladığını ifade etmektedir. Sanal ortamda birçok kişi ve arkadaşla iletişim kurduklarını, grup iletişimlerinin devam ettiğini, daha kolay bir araya geldiklerini ve kişilere ulaşabildiklerini, daha hızlı örgütlendiklerini, daha fazla sosyal ortamlara ve etkinliklere katıldıklarını, kolay ve hızlı haberleşme imkanına sahip olduklarını, bilgi alışverişi ve paylaşımı ile fikirlerini ifade ettiklerini, ortak ilgi alanlarına göre iletişim kurduklarını ve birbirlerine yardımda bulunduklarını belirtmektedir.

4) Dijital kamusal alan grup iletişimi performansını artırır.

Tüm katılımcılar dijital kamusal alanın grup iletişimi performansını arttırdığını belirtmektedir. Dijital kamusal alandaki grup iletişiminde daha aktif, rahat ve kolay şekilde kendini rahat ifade edebilediklerini belirtmektedirler. Katılımcılar akrabaları, arkadaşları ve kendi meslek gruplarında olan kişilerle rahat bir şekilde iletişim kurduklarını, gerçek hayatta çekindikleri bazı durumların aksine sosyal gruplarda daha rahat davranabildiklerini ve grup iletişimi arttıkça iletişim performansınında arttığını belirtmektedirler. Bir katılımcı iletişim performasını arttırdığını fakat bu ortamın sanal bir ortam olduğunu ifade etmektedir.

5) Dijital kamusal alan grup iletişiminde yeni medya algısıly geleneksel grup iletişim algısını degiştirerek yalnızlaştırır.

7 katılımcı dijital kamusal alanın grup iletişiminde yeni medya algısıyla geleneksel grup iletişim algısını degiştirerek yalnızlaştırdığını, 2 katılımcı yalnızlaştırmadığını, 1 katılımcı ise gerçekle aynı olmamasına rağmen bu durumun hayatımıza çok fazla yerleştiğini ve insanların kabullendiğini belirtmektedir. Olumlu görüş bildiren katılımcılar somut ve gerçek duyguların olmaması, soğuk ve bireysel olması, gerçek duyguların yerine sanal ifadelerin kullanılması, soyut 
Yazıc1, T., Tuerxun, X. (2017). Group communication at digital public space: WeChat sample. International

Journal of Social Sciences and Education Research, 3(3), 966-980.

ve uzak olması, sadece kendi ilgi alanlarına ait gruplara katılım olması ve gelenekselden uzak olması nedeniyle bireyleri yalnızlaştırdığını belirtmektedir.

\section{Sonuc}

Habermas kamusal alan olması için kamu, ortak alan ve ortak tartı̧̧manın olmazsa olmaz öğeleri olduğunu söylemektedir. Sanal ortamda kamu olarak katılımcılar, grup iletişim platformları ve çevrimiçi topluluklardaki ortak tartışmalarda bireylerin kendi görüş ve fikirlerini, şikayet ve eleştirilerini rahatlıkla paylaşabildikleri bir çok konunun tartışmaya açık olduğu bir alan olarak göstermektedir (Zhu\& Hong, 2013, s.3).

WeChat kullanımı ile ilgili yapılan derinlemesine mülakat sonucunda dijital kamusal alan faaliyetine katılmak bireyleri mutlu eder değerlendirmesinde, katılımcılar dijital kamusal alandaki faaliyetlere katılma eyleminin, paylaşıma ve etkileşime dayalı iletişim ortamlarının sanal veya gerçeklik boyutunda farklılık gösterse de katılımcı ve paylaşımcı kamusal alan oluşturduğunu ve bireyleri mutlu ettiğini ifade etmektedirler.

Dijital kamusal alanın yalnızlaşmanın önüne geçmesi ile ilgili katılımcıların çoğu bireysel ve gerçek paylaşım açısından bireyi yalnızlaştırdığını ifade etmektedirler. Katılımcıların değerlendirmelerinde gerçek kamusal alan ve dijital kamusal alan karşılaştırmasında fiziksel gerçeklik boyutu öne çıkmaktadır.

Dijital ortamın yeni ilişki ağları kurmaya yardımcı olması görüşü ile ilgili katılımcıların çoğu özellikle ilgili duydukları konular ve sosyal ilişkiler kurmayı sağladığını, WeChat özelinde dijital kamusal alanın kullanıcılara avantajlar sağladığını ve sosyallik sağlayarak yeni ilişki ağları kurduklarını belirtmektedir. Olumsuz anlamda ilişkilerin gerçek olmadığı, sanal ortam olduğu için sağlıksız ve kısa süreli ilişkiler olduğu belirtilmektedir.

Dijital kamusal alanda grup iletişimi bağlamında katılımcılar tarafından yapılan değerlendirmelerde;

Dijital kamusal alan sunduğu ortamda kullanıcıyı yalnızlaştırır değerlendirmesinde katılımcıların yarısı bireyi yalnızlaştırdığını, diğer katılımcılar da yalnızlaştırmadığını ifade etmektedir. Olumsuz görüş bildiren katılımcılar gerçek hayatta sosyallaşme olmaması ve sanal bir ortam olmasından dolayı bireyin aslında yalnız olduğunu ifade etmektedir. Diğer katılımcılar grup içinde aktif kullanım, paylaşım ve iletişim olması durumunda ve yeni insanlarla tanışıldığında bireyi yalnızlaştırmadığını belirtmektedir.

Dijital kamusal alan katılımcının katılım seviyesini arttırır değerlendirmesinde katılımcıların çoğu katılım seviyesini arttırdığını belirtmektedir. Kişilerin yüzyüze iletişime göre daha kolay iletişim kurabildiklerini, bilgi alışverişinde bulunduklarını, çeşitli sosyal aktivitelere katıldıklarını, gerçek hayata göre daha kolay ve daha fazla katılım imkanı sağladığını belirtmektedir.

Dijital kamusal alan toplumsal katılımı sağlar değerlendirmesinde tüm katılımcılar dijital kamusal alanın toplumsal katılımı sağladığını ifade etmektedir. Sanal ortamda birçok kişi ve arkadaşla grup iletişimi kurduklarını ve daha fazla kişiye ulaşabildiklerini, daha hızlı örgütlendiklerini, sosyal ortamlara ve etkinliklere katıldıklarını, kolay ve hızlı haberleşme imkanına sahip olduklarını, fikirlerini ifade ettiklerini ve birbirlerine yardımda bulunduklarını belirtmektedir. 
Yazıcı, T., Tuerxun, X. (2017). Dijital kamusal alanda grup iletişimi: WeChat örneği. International Journal of Social Sciences and Education Research, 3(3), 966-980.

Dijital kamusal alan grup iletişimi performansını artırır değerlendirmesinde tüm katılımcılar dijital kamusal alanın grup iletişimi performansını arttırdığını belirtmektedir. Grup iletişiminde daha aktif ve kendini daha rahat ifade edebildiklerini belirtmektedirler. Bulundukları gruplarda gerçek hayatta çekindikleri bazı durumların aksine daha rahat davranabildiklerini ve grup iletişimi arttıkça iletişim performansınında arttığını belirtmektedirler.

Dijital kamusal alan grup iletişiminde yeni medya algısıyla geleneksel grup iletişim algısını degiştirerek yalnızlaştırır değerlendirmesinde katılımcılar gerçek duyguların yerine sanal ifadelerin kullanılması, soyut ve uzak olması, sadece kendi ilgi alanlarına ait gruplara katılım olması ve gelenekselden uzak olması nedeniyle bireyleri yalnızlaştırdığını belirtmektedir.

WeChat uygulamasının kullanım alanları ve çalışmanın Çin'de yaşayan bireylerle gerçekleştirilmesi noktasından hareketle, katılımcılar WeChat uygulamasını çok etkin şekilde kullanmaktadır. Kullanıcılar bireysel gelişimleri ve toplumsal ilişkilerinin sürekliliği açısından hayatlarında önemli bir sosyal ortam, önemli bir kamusal alan oluşturduğu ve bu kamusal alanın çok etkin bir şekilde kullanıldığı sonucuna ulaşılmaktadır. Geleneksel ortamlardan ayıran özellikleri olmasına karşın dijital ortamların kamusal alan yaratması ve bu katılımın sürekli olması kamusal alanın etkinliğini arttırmaktadır. Bu nedenle WeChat grup iletişiminin sanal kamusal alanın parçası yada özel bir kamusal alan oluşturduğu sonucu ortaya çıkmaktadır.

\section{Kaynakça}

Dijk, V. D. (2016). Ağ toplumu, Epsilon Yayınc1lık, 40-41.

Ercins, G. (2013). Demokrasinin bir ön koşulu olarak kamusal alan ve Türkiye'de kamusal alan algisı. http://11bfderg1.cumhuriyet.edu.tr/archive/ındekıler, 141.

Habermas, J. (2004). "Kamusal alan” kamusal alan, ed. Meral Özbek, İstanbul, Hil Yayın, 95-102.

Hazar, M., (2011). Sosyal medya bağımlılığı bir alan çalışması. İletişim Kuram ve Araştırma Dergisi, 32.

Kesim, M., (2008), Uzaktan eğitim teknolojilerindeki yönelimler IPV4 , Uluslararası Uzaktan Eğitim Konferans1, Ekim.

Köksal, Y. \& Özdemir Ş. (2013). Bir iletişim aracı olarak sosyal medyanın tutundurma karması içerisindeki yeri üzerine bir inceleme. Süleyman Demirel Üniversitesi İktisadi ve İdari Bilimler Fakültesi Dergisi, c1lt: 18,1 .

Kwon, E. \& Y. Sung, (2011). Follow me! Global marketers twitter use. Journal of Interactive Advertising, Vol 12, No1, Fall, s.4-16.

Megep (2012). Halkla ilişkiler ve organizasyon hizmetleri: Grup iletişimi. Milli Eğitim Bakanlığı, 5.

Sayımer, İ. (2014). Yeni medya ortamlarında ağlar oluşturan toplumsal hareket deneyimleri. Elektronik Mesleki Gelişim ve Araştırma Dergisi (Ejoir), cilt:2, 97-98.

Varol, A. (2010). Bilgi toplumunda kamusal alan. Sosyal Bilimler Dergisi, (4), 126-127.

Yükselbaba, Ü. (2008). Habermas'da kamusal alan/özel alan ayrımı. Doktora Tezi, İstanbul Üniversitesi Sosyal Bilimler Enstitüsü, İstanbul, 72.

Zhu, Z. \&Hong, G. (2013). 网络中是否存在公共领域? --基于哈贝马斯公共领域 (Whether the network exists in the public domain? Based on Habermas public sphere). http://sociology.cssn.cn/webpic/web/sociology/upload/2013/09/d20130913211735488.pdf

https://tr.wikipedia.org/wiki/WeChat, Erişim tarihi: 05.03.2017. 
Yazıc1, T., Tuerxun, X. (2017). Group communication at digital public space: WeChat sample. International

Journal of Social Sciences and Education Research, 3(3), 966-980.

\section{Extended abstract in English}

Technological differences in human life and new communication methods have changed the way of living the concept of social life. Social media environments one of the new forms of socialization, create common and virtual environments in which disparate people in common interests or professions can communicate through announcement or exchange of information without having to recognize each other. It is an innovation provided by the communication technology that social media can create individual media, create their own media and share them on the social media by means of photographs, videos, written texts of an individual or group.

Habermas says that public space is an indispensable element of public space, common space and common debate. Participants in the public environment in the virtual environment represent an area where group discussions of communicative platforms and online communities are open to debate about many of the topics for which individuals can easily share their views and opinions with their complaints and criticisms (Zhu\& Hong, 2013, s.3).

The WeChat application, which has been widely used in social media recently, is a free, next generation mobile communication tool that combines text, voice and video chat features, with more than 700 million users worldwide, based in China. Providing the public space among the participants, WeChat is carrying digital public space by providing communication and interaction as well as the emergence of differentiated societies according to personal characteristics.

Purpose of the study examines the communication platform in terms of the importance and use of group communication in the context of public space and to reveal its social effect, the social networking site WeChat, which is used extensively in China. The study is a phenomological study using qualitative research methods. The universe of this work was identified as users with experience in this platform between 16 and 66 years of age.

In this study a semi-structured interview forms were used as data research methods. Participants were not given their names by observing the confidentiality of the research and participants were identified with codes such as K1, K2, K3. Interview form has been determined as "Digital Public Domain Group Communication" and this method is taken as the basis. Before the interview, there was a brief description of the participants' digital public space. The interview form consists of the questions under the two headings and the opinions emerging in this direction. The evaluation fields included in the interview forms are as follows:

A-) Visions related to digital public site

1) The individual is happy to participate in the digital public space activity.

2) Digital public space leads to isolation.

3) Digital public space helps to establish new relationship networks.

B-) Digital public opinions about the group contact

1) Digital public space isolated participation in the environment where digital media is present.

2) Increase the participation level of the digital public space participant.

3) Digital public space provides social participation.

4) Digital public domain improves group communication performance. 
Yazıcı, T., Tuerxun, X. (2017). Dijital kamusal alanda grup iletişimi: WeChat örneği. International Journal of Social Sciences and Education Research, 3(3), 966-980.

5) Digital public space loses communication in group communication by changing traditional group communication perception by new media sense.

Participants use WeChat very effectively, moving from the point of use of the WeChat application and the realization of the work with individuals living in China. Users create an important social and public space in their lives in terms of their individual development and the continuity of their social relations, and they use this public space very effectively. Participation in this group communication, independent of time and space is evaluated positively by participants as they participate according to their specific areas of interest, professional groups and kinship relations. In group communications, information exchange is intense, communicating between groups indicates that they both participate in activities and help people who need help. With these views, the participants state that the individual is actually in individual communication in the virtual environment, and that the socialization in these environments isolates the person. Contrary to the fact that they do not alone, according to the real life, it is expressed by the participants that they make the person more social because of the ability of the individuals to be more courageous and active. As a result of the evaluations carried out on the participants in the interview, it is revealed that the WeChat group communication constitutes part of the virtual public space or constitutes a private public space, the participants are happy to be in this public space, and they provide a public social space because they are in constant communication and sharing. 